\title{
Parts-per-Million of Polyethylene Glycol as a Non-Interfering Blocking Agent for Homogeneous Biosensor Development
}

Biwu Liu, Po-Jung Jimmy Huang, Xu Zhang, Feng Wang, Rachel Pautler, Alexander C-F. Ip, and Juewen Liu*

Department of Chemistry and Waterloo Institute for Nanotechnology, University of Waterloo, 200 University Avenue West, Waterloo, Ontario, Canada N2L 3G1.

Email: liujw@uwaterloo.ca

This document is the Accepted Manuscript version of a Published Work that appeared in final form in Analytical Chemistry copyright ( American Chemical Society after peer review and technical editing by publisher. To access the final edited and published work see Liu, B., Huang, P.-J. J., Zhang, X., Wang, F., Pautler, R., Ip, A. C., \& Liu, J. (2013). Parts-per-Million of Polyethylene Glycol as a Non-Interfering Blocking Agent for Homogeneous Biosensor Development. Analytical Chemistry, 85(21), 10045-10050. https://doi.org/10.1021/ac4024654 


\begin{abstract}
.
Many homogeneous assays are complicated by the adsorption of probe molecules by the surface of reaction vessels, which are often made of polypropylene or polystyrene-based plastics. To solve this problem, many protein and surfactant-based blocking agents are used. However, these blockers may interfere with intended assays by sequestering transition metal ions, inducing protein denaturing, generating air bubbles or making pores in membranes. Coating surfaces with polyethylene glycol (PEG) through covalent linkages have been proven to be an effective method to minimize protein adsorption. However, this method is more difficult to apply on plastic surfaces and is quite expensive. While unmodified PEG is often considered as a non-adsorbing polymer, in this Technical Note, we report that PEG at very low ppm can still effectively block plastic surfaces. This method works for DNA, protein and liposome-based assays as long as the molecular weight of PEG is larger than 2000. PEG works due to multivalent hydrophobic interaction from its repeating methylene units. This Technical Note will not only facilitate biosensor development, but also enhance our understanding of the interaction between various molecules and plastic surfaces.
\end{abstract}




\section{Introduction}

Two assay formats are commonly used for biosensor development. One is to immobilize enzymes, antibodies or DNA probes on a surface (Figure 1A). ${ }^{1,2}$ Examples of such include enzyme electrodes, immunoassays and DNA microarrays. To obtain an optimal performance, non-specific interactions with the surface need to be minimized, which is sometimes achieved by blocking agents (e.g. bovine serum albumin or BSA for nitrocellulose; mercaptohexanol or thiolated polyethylene glycol (PEG) for gold surface, Figure 1B). ${ }^{3,4}$ In the other assay format (i.e. homogeneous assay), all the reagents are mixed in a vessel and reactions are intended to take place only in the solution phase. ${ }^{5-11}$ Hydrophobic plastics such as polystyrene and polypropylene are the most common container materials for making disposable microplates and microtubes. The interaction between biomolecules and surfaces in homogeneous assays is often ignored. However, biomolecules may still be adsorbed by these surfaces (Figure 1C). This may not significantly affect assay results at high biomolecular concentration. At low concentration (e.g. $\sim 10-50 \mathrm{nM}$, monolayer capacity), however, a large fraction of molecules might be adsorbed by the container surface, producing false or inconsistent results. This concentration range is now routinely used partly due to analytical instruments becoming more and more sensitive. Therefore, surface adsorption appears to be an increasingly important problem.

To block un-intended adsorption, BSA and surfactants are often employed. These molecules can effectively coat hydrophobic surfaces and expose hydrophilic head groups or protein domains. ${ }^{12}$ However, they may interfere with assays due to their complex chemical structures. ${ }^{13,14}$ For example, proteins-based blockers compete for transition metal cofactors, complicate aptamer selections, and are expensive. Surfactants, on the other hand, are quite toxic and may cause membrane leakage or protein denaturation. Generation of air bubbles is another adverse effect of these blocking agents.

PEG is an important antifouling polymer to prevent protein adsorption, ${ }^{15-17}$ although PEG has also been reported to form complexes with certain proteins. ${ }^{18}$ For this purpose, PEG is often covalently grafted onto a surface (Figure 1D) via thiol, ${ }^{19}$ polyamine, ${ }^{20}$ polyacrylic acid, ${ }^{21}$ polylactide, ${ }^{22}$ 
dihydroxyl, ${ }^{23}$ or streptavidin linkages. ${ }^{24}$ Unmodified PEG has the advantage of being cost-effective and easy to use, but it is under-explored as a surface blocker. ${ }^{25,26}$ We recently reported the use of PEG as a stabilizer for nanoparticles, ${ }^{27-29}$ and PEG is also a commonly used artificial crowding agent. ${ }^{30-32}$ With the common perception that PEG is an anti-fouling molecule, unmodified PEG appears to be a poor blocker. In this Technical Note, we report that very diluted and unmodified PEGs can effectively block plastic surfaces for homogeneous assays involving DNAs, proteins or lipids (Figure 1E).

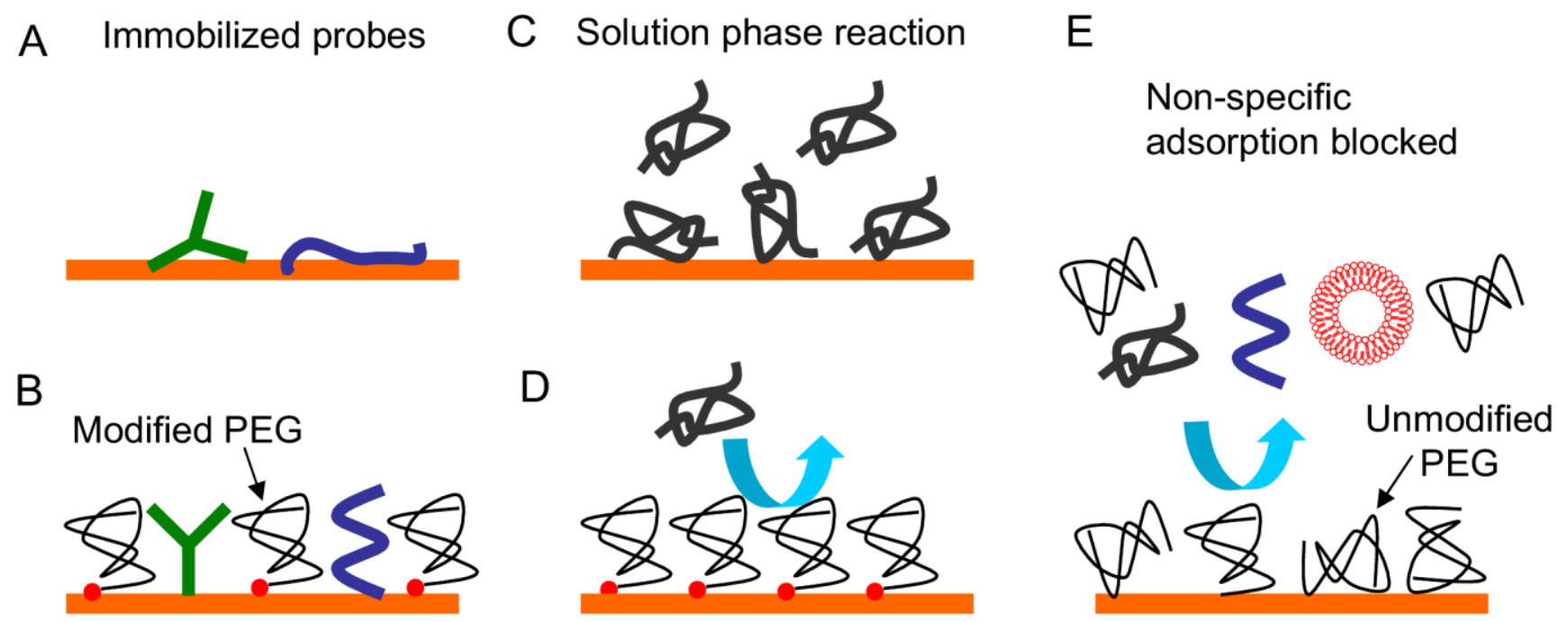

Figure 1. Schematics of biomolecules interacting with surfaces and the effect of blocking agents. (A) Biomolecular probes immobilized on the surface may denature due to non-specific interactions with the surface. (B) Blocking the surface with molecules such as PEG via a covalent linkage can minimize non-specific surface interaction. (C) For reactions in solution phase (homogeneous assays), the container surface might also adsorb biomolecules, which can be avoided by blocking the surface with modified PEG as shown in (D). (E) The strategy in the current work of using unmodified PEG for blocking surfaces. 


\section{Materials and Methods}

Chemicals. All the DNA samples were from Integrated DNA Technologies Inc. (Coralville, IA). All the phospholipids were from Avanti Polar Lipids (Alabaster, AL). All the PEG samples, low binding half volume black 96-well plates made of polystyrene, and polypropylene microcentrifuge tubes were from VWR. VIM-2 were over-expressed and purified following the literature procedures. ${ }^{33}$ BSA, Triton X-100, and disodium calcein were from Sigma-Aldrich. Nitrocefin was from TOKU-E (Bellingham, WA). FAM-labeled PEG 10k was from Nanoce Inc (Boston, MA). All the salts and buffers were from Mandel Scientific Inc (Guelph, ON, Canada).

DNA related experiments. If not otherwise noted, the 96-well plate was first carefully washed ethanol and DI water and dried. In a typical experiment, $1 \mu \mathrm{L}$ of $1 \mu \mathrm{M}$ FAM-labeled DNA was added into 99 $\mu \mathrm{L}$ of HEPES buffer ( $5 \mathrm{mM}, \mathrm{pH} 7.6)$ containing various concentrations of $\mathrm{NaCl}(0,50 \mathrm{mM}, 100 \mathrm{mM}$, and $500 \mathrm{mM}$ ). Then the fluorescence was scanned for $3 \mathrm{hr}$ on a microplate reader by exciting at $485 \mathrm{~nm}$ (Infinite F200 Pro, Tecan). The same experiment was then repeated by including a designated concentration of PEG in the buffer before the DNA was added (10 min pre-incubation time). To study the effect of PEG molecular weight (MW) and concentration, $100 \mathrm{mM} \mathrm{NaCl}$ was used and the DNA was FAM-T 15 .

VIM-2 assays. In a typical assay, VIM-2 stock solution was prepared at $10 \mu \mathrm{g} / \mathrm{mL}$ concentration in 50 mM HEPES buffer ( $\mathrm{pH} 7.3$ ) in the presence of various blocking agents (BSA, Triton X-100, or PEG). The samples were allowed to sit in microcentrifuge tubes for a designated period of time to allow adsorption by the tube wall before the assay. The final VIM-2 concentration was $12.5 \mathrm{ng} / \mathrm{mL}$ in the microplate for nitrocefin assay (nitrocefin $=100 \mu \mathrm{M}$ ). The final reaction buffer was $50 \mathrm{mM}$ HEPES (pH 7.3) with $100 \mu \mathrm{M} \mathrm{ZnCl}_{2}$.

Liposome related assays. 1,2-dioleoyl-sn-glycero-3-phosphocholine (DOPC), 1,2-dioleoyl-snglycero-3-phospho-(1'-rac-glycerol), sodium salt (DOPG) and 1,2-dioleoyl-3-trimethyl ammonium- 
propane (DOTAP) liposomes with $1 \%$ rhodamine (Rh)-DOPE (1,2-dioleoyl-sn-Glycero-3phosphoethanolamine) was prepared by the standard extrusion method through $100 \mathrm{~nm}$ pore described previously. ${ }^{34}$ The final liposome concentration was $2.5 \mu \mathrm{g} / \mathrm{mL}$ dispersed in buffer $(100 \mathrm{mM} \mathrm{NaCl}, 10$ $\mathrm{mM}$ HEPES, $\mathrm{pH}$ 7.6) in the 96-well plate. The fluorescence was excited at $532 \mathrm{~nm}$ using the microplate reader. The preparation of calcein encapsulated DOPC liposomes followed previously published protocols and the liposomes were purified using a Pd-10 desalt column. ${ }^{35}$ The eluted liposome was diluted 500 times in the buffer and transferred to the plate. For some experiments, we intentionally used a new plate (unwashed) to keep the original surfactants to show the liposome leakage effect. After $1 \mathrm{hr}$, a final of $0.05 \%$ Triton X-100 was added to fully rupture the liposomes.

PEG adsorption. FAM-labeled PEG 10k was used to study PEG adsorption. Various concentrations of PEG 10K were added to $5 \mathrm{mM}$ HEPES buffer with a final volume of $100 \mu \mathrm{L}$ (final $[\mathrm{PEG}]=10,20,50$, 100, and $200 \mathrm{nM})$. The fluorescence was monitored for $1 \mathrm{hr}$.

\section{Results and Discussion}

DNA assays. Nucleic acids, proteins and lipids are among the most commonly used molecules for biosensor development. Herein, we study representative molecules from each class. First, FAM-labeled 15-mer DNA homo-polymers $(10 \mathrm{nM})$ were added to a disposable 96-well plate in the presence of various $\mathrm{NaCl}$ concentrations. The stability of fluorescence signal was monitored for $3 \mathrm{hr}$. FAM-A $\mathrm{A}_{15}$ has stable fluorescence with up to $100 \mathrm{mM} \mathrm{NaCl}$, while $\sim 60 \%$ fluorescence is lost with $500 \mathrm{mM} \mathrm{NaCl}$ (Figure 2A). FAM-T 15 yields very unstable signals; even $50 \mathrm{mM} \mathrm{NaCl}$ results in $\sim 80 \%$ loss (Figure 2B). The initial fluorescence of $\mathrm{FAM}-\mathrm{C}_{15}$ increases with increasing salt concentration, but drastic quenching occurs with more than $50 \mathrm{mM} \mathrm{NaCl}$ (Figure 2C). FAM-G 15 gives the most stable fluorescence, where fluorescence drops only $20 \%$ with $500 \mathrm{mM} \mathrm{NaCl}$ (Figure 2D). In general, adding $\mathrm{NaCl}$ appears to push the DNAs towards the surface and mask fluorescence signal. Note that the fluorescence was quite stable for all the samples in the absence of salt. $\mathrm{NaCl}$ also affects the initial fluorescence intensity of 
DNA, which is attributed to fluorescence quenching by the bases and DNA changes conformations as a function of salt concentration. ${ }^{36}$ The lack of a stable fluorescence makes it difficult to carry out related assays. This set of experiments indicates that the polystyrene surface is likely to be negatively charged, and $\mathrm{NaCl}$ screens the electrostatic repulsion with negatively charged DNA. While poly-T DNA adsorption is often very weak (e.g. on gold or graphene oxide), its fast adsorption onto the plastic surface may be attributed to the lack of internal structures and the bases are exposed to interact with the plastic surface. Poly-G and poly-A DNAs, on the other hand, are prone to form various secondary structures in the presence of salt to shield its bases, leading to more stable signal. Since salt is often required for DNA-based assays, non-specific adsorption of DNA poses an analytical challenge for biosensor development. In the presence of 0.5\% PEG 20k (i.e. MW = 20,000), none of the samples showed fluorescence decrease with up to $500 \mathrm{mM} \mathrm{NaCl}$ (Figure 2E-H). Therefore, PEG can be used as an effective blocker in this case.
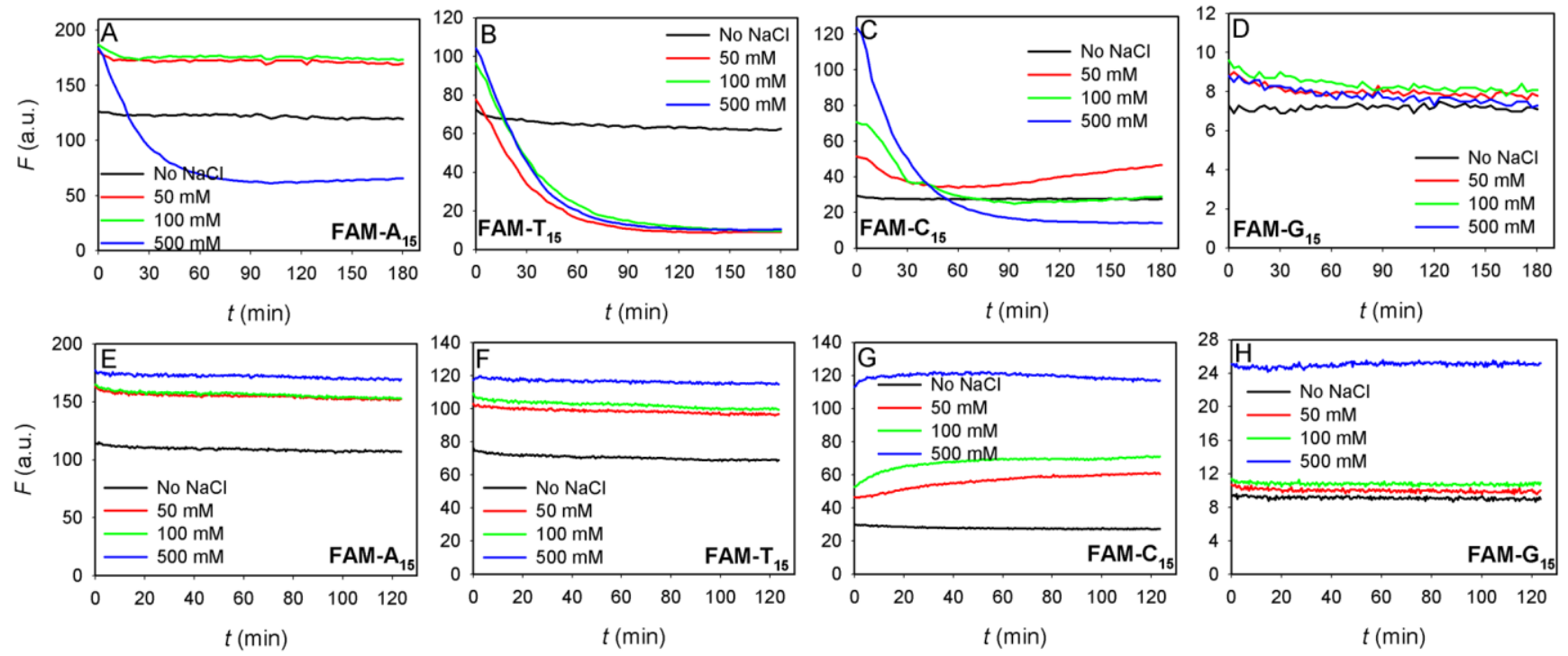

Figure 2. Variation of fluorescence signals of FAM-labeled 15-mer DNA in a 96-well plate with different concentrations of $\mathrm{NaCl}$ and DNA sequences: (A) FAM-A 15 , (B) FAM-T 15 , (C) FAM-C 15 , (D) FAM-G 15 . The same experiments performed with $0.5 \%$ of PEG 20K: (E) FAM-A 15 , (F) FAM-T 15 , (G) FAM-C $15,(\mathrm{H})$ FAM-G 15 . 
Next, we aim to push the limit of the MW and concentration of PEG for achieving effective blocking. Since FAM-T 15 has the most pronounced adsorption by the plate, it was used for this study. No effective blocking was detected with up to $0.1 \%$ PEG 200 (Figure 3A). Moderate blocking effect was achieved with $0.1 \%$ PEG 400 and complete blocking was achieved with $0.01 \%$ PEG $1 \mathrm{k}$. It is interesting to note that PEG 2k, 4k, 8k, 20k, and 35k all exhibited a similar blocking effect (Figure 3D$\mathrm{H})$, where $0.00001 \%$ PEG (0.1 ppm) failed to inhibit DNA adsorption but $0.0001 \%$ PEG (1 ppm) and above showed full stabilization of the fluorescence signal. Additional data with smaller PEG concentration increase are supplied in Figure S1. This experiment leads to non-trivial conclusions. First, since a minimal PEG MW is needed, the interaction between PEG and surface is likely through multivalent weak forces on each repeating unit and later we will show evidence for hydrophobic interaction. A PEG chain of 2000 MW appears to be a stable attachment block, which agrees with that reported in using PEG as an crowding agent. ${ }^{37}$ Second, at a fixed w/w concentration, the number of PEG 35k molecules is only $~ 5.7 \%$ of that PEG 2k. Since both can achieve a similar blocking effect, the polymer chains are in effective contact with the surface. 

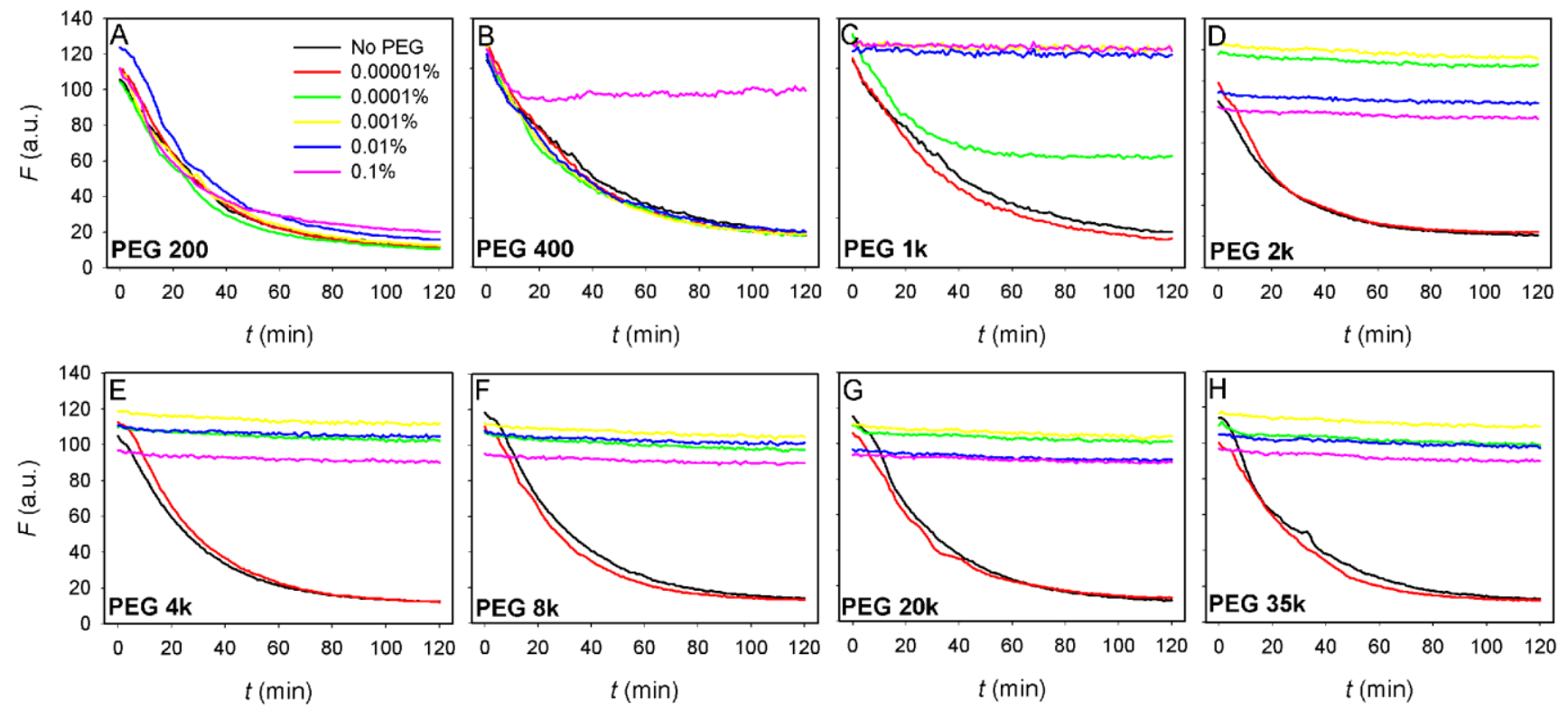

Figure 3. Variation of fluorescence signals of FAM- $\mathrm{T}_{15}$ in a $96-$ well plate in the presence of different PEG MW: (A) PEG 200, (B) PEG 400, (C) PEG 1k, (D) PEG 2k, (E) 4k, (F) PEG 8k, (G) PEG 20k and (H) PEG 35k.

Protein assays. Many protein enzyme assays and related drug screening take place in disposable plasticware. With high activity, a low concentration of enzyme is sufficient for each assay. Therefore, adsorption of enzymes by the assay container may also result in large data variations. VIM-2 is an important metallo- $\beta$-lactamase using $\mathrm{Zn}^{2+}$ as a cofactor. ${ }^{33}$ Nitrocefin is a typical substrate for this assay, where its original color is light yellow. After hydrolysis, the color is changed to orange due to an absorbance increase at $482 \mathrm{~nm}$ (Figure 4A). Directly diluting the enzyme in buffer without blocking agent results in a quick reduction of its activity. If the rate of the color change is plotted, we can see that the activity dropped to $\sim 15 \%$ of the original value after incubating the diluted enzymes for $3 \mathrm{hr}$ in polypropylene tubes before the assay is started (Figure 4E). This is again attributed to the adsorption of the enzyme by the plastic container. 

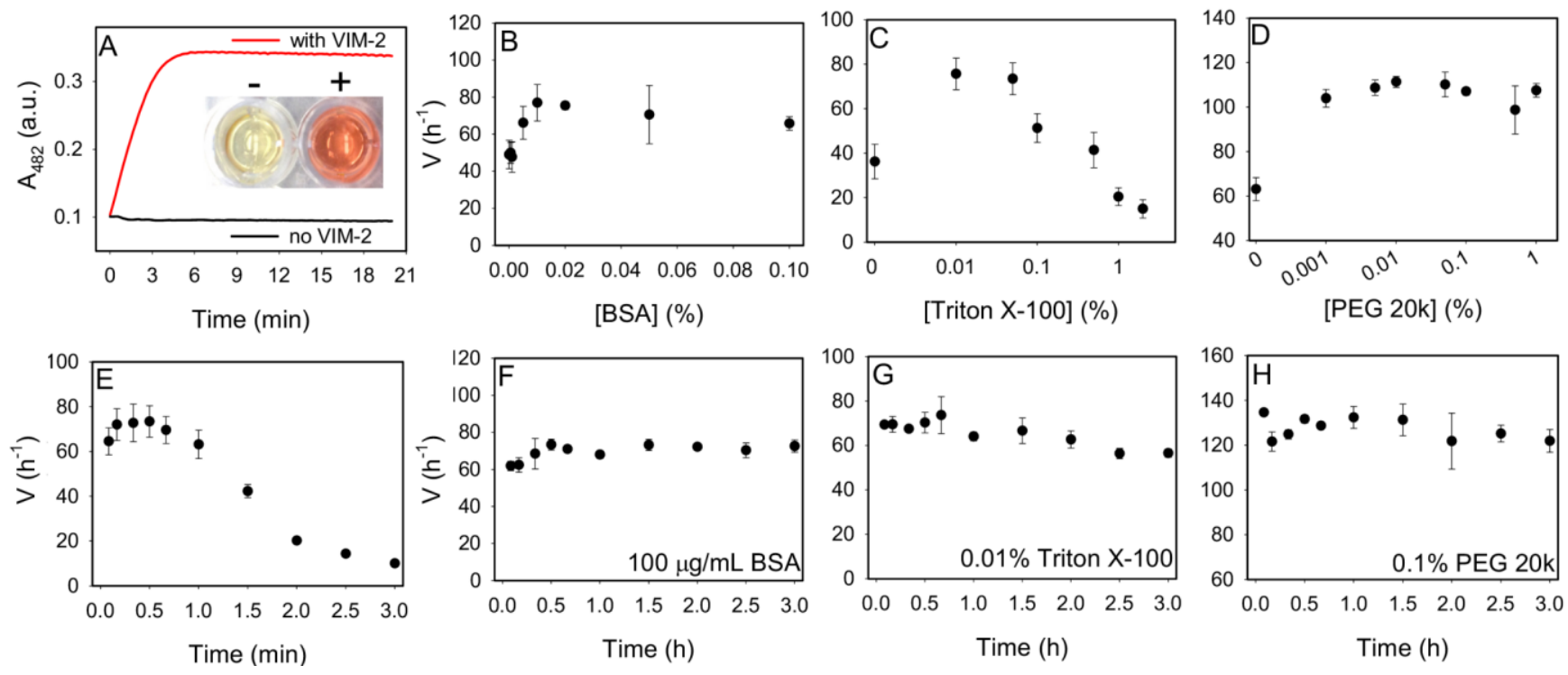

Figure 4. (A) Kinetics of nitrocefin changing color in the presence or absence of VIM-2. Inset: A photograph showing the color of nitrocefin for these two samples. Activity of the VIM-2 enzyme after 30 min incubation in a plastic container in the presence of various concentrations of BSA (B), Triton X-100 (C) or PEG 20k (D). Activity of the enzyme incubated with a certain concentration of BSA (F), Triton X-100 (G) or PEG 20k (H) as a function of incubation time. (E) Reducing of the enzyme activity as a function of incubation time before reaction.

To solve this problem, we compared a few blocking agents. BSA is recommended for the VIM2 assay, ${ }^{38}$ where the enzyme activity is stable with more than $0.01 \%$ BSA (Figure 4B). We tested up to $0.1 \%$ BSA since even higher concentration of BSA generates bubbles that complicate the assay. With $0.01 \% \mathrm{BSA}$, the enzyme remained stable for the $3 \mathrm{hr}$ we tested (Figure $4 \mathrm{~F}$ ). Triton $\mathrm{X}-100$ is another blocking agent often used for enzyme assays. In this particular case, we found that it has a stabilizing effect at low concentration but becomes an inhibitor at higher than $0.05 \%$ (Figure 4C). With $0.01 \%$ Triton X-100, the enzyme is quite stable in $3 \mathrm{hr}$ (Figure 4G). Next we tested PEG 20k, where the enzyme showed the same high activity from $0.001 \%$ to $1 \%$ (Figure 4D). With $0.1 \%$ PEG 20k, the 
activity is stable in $3 \mathrm{hr}$ (Figure $4 \mathrm{H})$. Since PEG is not a surfactant, it does not generate bubbles even at high concentrations. It is also interesting to note that the enzyme activity is about $40 \%$ higher in PEG than in BSA or Triton X-100. It might be related to the minimal interaction between PEG and the enzyme. For example, BSA might compete with VIM-2 for $\mathrm{Zn}^{2+}$ and Triton might denature the enzyme at high concentrations.

Lipid assays. Lipid-based assays often involve liposomes. We respectively prepared rhodamine (Rh) labeled DOPC (zwitterionic), DOPG (anionic) and DOTAP (cationic) liposomes, where they all showed 30-40\% adsorption by the plate surface (Figure 5A-C, black traces). With 0.01\% PEG 20k, effective blocking was achieved (red traces), even for positively charged liposomes. Some coated surfaces might block the plate surface, but may induce other artifacts. For example, we used a new 'low binding' plate from the vendor and the fluorescence of calcein encapsulated DOPC liposomes continued to increase in $30 \mathrm{~min}$, when the majority of the liposomes leaked since adding Triton X-100 did not induce much further fluorescence enhancement (Figure 5D, black trace). Note that we encapsulated $100 \mathrm{mM}$ calcein in the liposomes, resulting in self-quenched fluorescence. After washing the same plate with ethanol and water, the same liposome was very stable in $0.01 \%$ PEG 20k, where adding Triton X-100 at 60 min induced a significant fluorescence enhancement. 

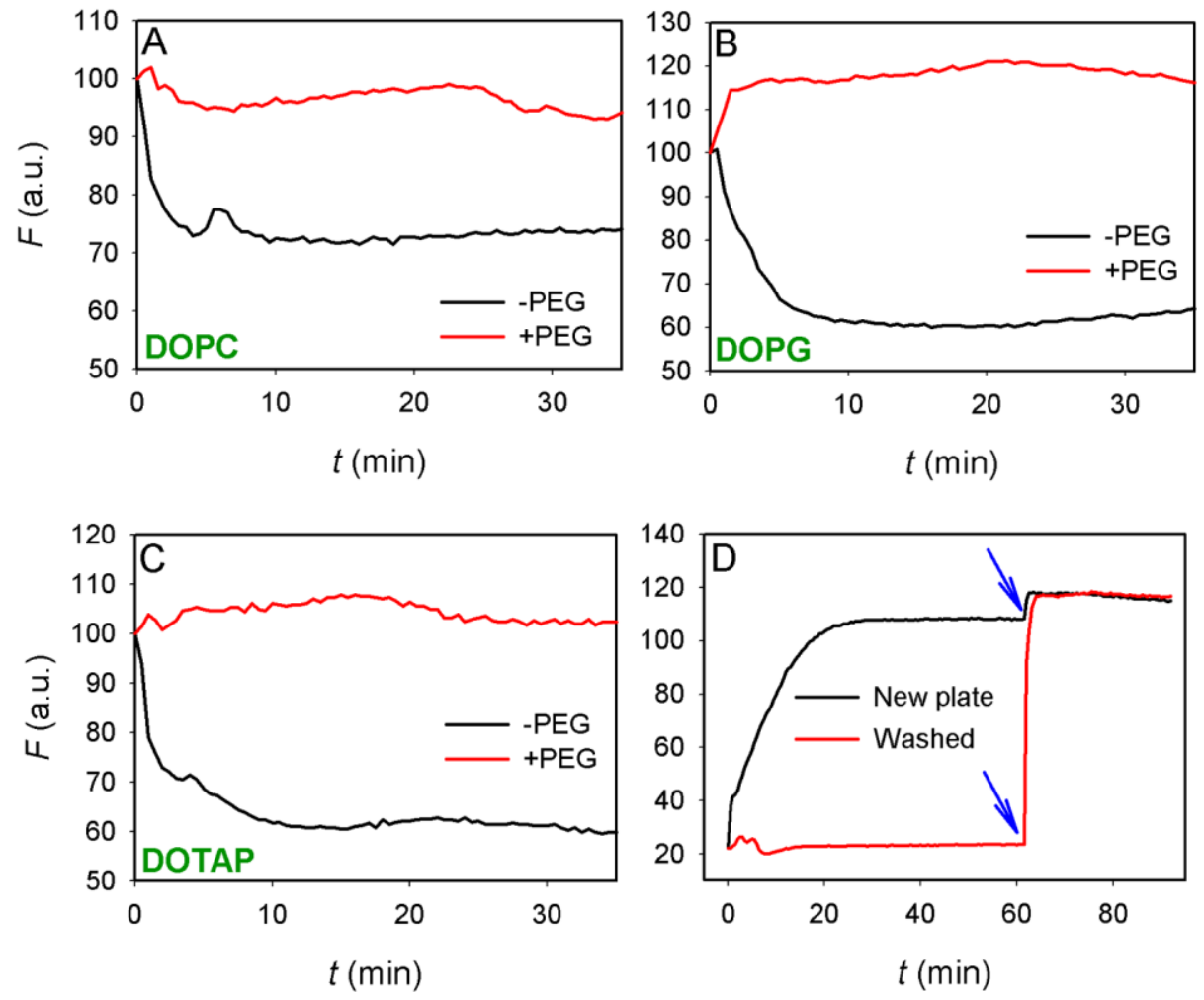

Figure 5. (A) Fluorescence signal of Rh-labeled DOPC (A), DOPG (B) and DOTAP (C) liposomes with and without $0.01 \%$ PEG 20k. (D) Fluorescence signal of calcein encapsulated DOPC liposomes in a new surfactant coated plate (black trace) and after washing with ethanol and PEG (red trace). The arrow heads indicate the time when Triton X-100 was added.

Adsorption of PEG. Since PEG is often considered to be a non-adsorbing polymer, to confirm binding between PEG and plastic surface, we used FAM-labeled PEG 10k. Similar time-dependent fluorescence drop was observed, where equilibrium was reached in a few minutes at high PEG concentration (e.g. $200 \mathrm{nM}$ or $2 \mathrm{ppm}$, Figure 6A, blue trace). It takes longer time for lower PEG concentration to reach equilibrium, indicating that the adsorption is a slow reaction (Figure 6B). Based on the amount of fluorescence quenching, we obtained Langmuir adsorption isotherm (Figure 6C), from which the capacity is calculated to be $40 \mathrm{nM}$ PEG 10k. With a volume of $100 \mu \mathrm{L}$, the capacity is $2.4 \times 10^{12}$ PEG 10k on the surface. The geometric surface area of each plate well is estimated to be 
$1.05 \times 10^{-4} \mathrm{~m}^{2}$. Then the occupied surface area of each PEG 10k molecule on plate well surface is 4.38 $\times 10^{-17} \mathrm{~m}^{2}$, yielding a diameter of $6.6 \mathrm{~nm}$, which agrees well with the expected hydrodynamic size of this polymer. ${ }^{39}$ PEG adsorption is weakened by ethanol (Figure S2), which is a strong evidence that hydrophobic interaction plays a major role for PEG adsorption by plastic surface. In addition, even $3 \mathrm{M}$ $\mathrm{NaCl}$ cannot inhibit PEG adsorption (Figure S3), confirming that electrostatic interaction is not important.
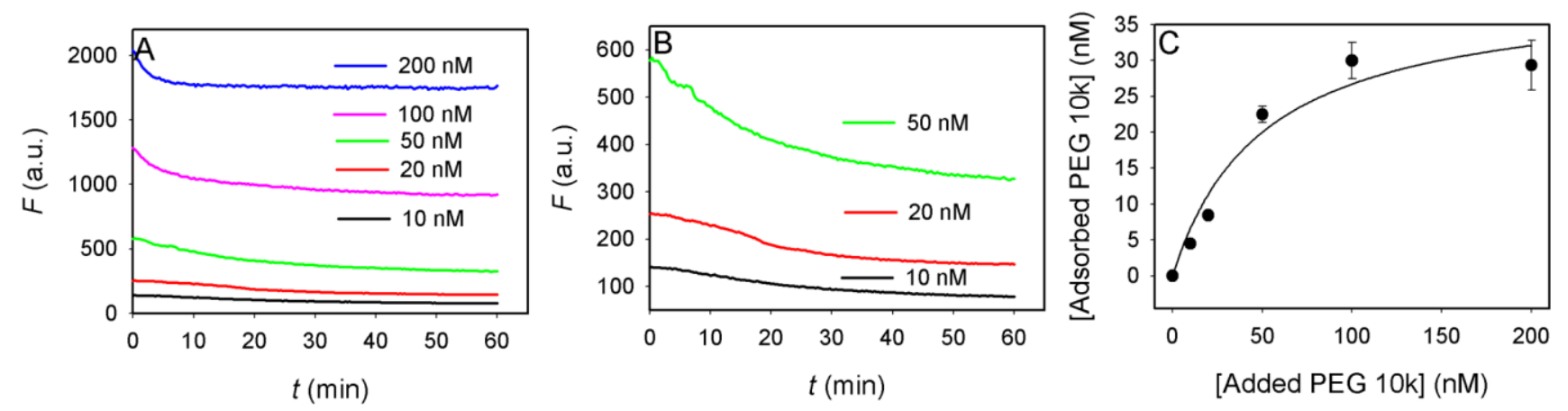

Figure 6. (A, B), Kinetics of FAM-PEG 10k adsorption by the plate. (B) the lower concentration portion of (A). (C) Adsorption isotherm of FAM-PEG 10k onto a 96-well plate.

\section{Conclusions}

In summary, we reported an exceptionally simple but very effective method to block plastic surfaces. The reason for the blocking effect is related to the adsorption of PEG by the surfaces. It is quite striking that even $1 \mathrm{ppm}$ of PEG is highly effective. Considering its simple chemical structure compared with protein or surfactant-based blockers, PEG at low ppm concentration is unlikely to interfere with biochemical reactions. We believe this technical advance will facilitate related biosensor and assay development work. At the same time, it enhances our understanding on the interaction between plastic surfaces and biomolecules. 


\section{Supporting Information}

Additional DNA adsorption data in PEG, adsorption of PEG in ethanol and high salt buffers. This material is available free of charge via the Internet at http://pubs.acs.org.

\section{Acknowledgment}

We thank Dr. Genevieve Labbe for assistance for purification of VIM-2. Funding for this work is from the University of Waterloo, the Canadian Foundation for Innovation, Ontario Ministry of Research \& Innovation, Canadian Institutes of Health Research, and the Natural Sciences and Engineering Research Council (NSERC) of Canada. 


\section{References}

(1) Templin, M. F.; Stoll, D.; Schrenk, M.; Traub, P. C.; Vohringer, C. F.; Joos, T. O. Trends Biotechnol. 2002, 20, 160-166.

(2) Brown, P. O.; Botstein, D. Nat.Genet. 1999, 21, 33-37.

(3) Tovey, E. R.; Baldo, B. A. J. Biochem. Biophys. Methods 1989, 19, 169-183.

(4) Herne, T. M.; Tarlov, M. J. J. Am. Chem. Soc. 1997, 119, 8916-8920.

(5) Wang, K. M.; Tang, Z. W.; Yang, C. Y. J.; Kim, Y. M.; Fang, X. H.; Li, W.; Wu, Y. R.; Medley, C. D.; Cao, Z. H.; Li, J.; Colon, P.; Lin, H.; Tan, W. H. Angew. Chem. Int. Ed. 2009, $48,856-870$.

(6) Zhang, H.; Li, F.; Dever, B.; Li, X.-F.; Le, X. C. Chem. Rev. 2013, 113, 2812-2841.

(7) Liu, J.; Cao, Z.; Lu, Y. Chem. Rev. 2009, 109, 1948-1998.

(8) Rosi, N. L.; Mirkin, C. A. Chem. Rev. 2005, 105, 1547-1562.

(9) Lubin, A. A.; Plaxco, K. W. Acc. Chem. Res. 2010, 43, 496-505.

(10) Li, D.; Song, S. P.; Fan, C. H. Acc. Chem. Res. 2010, 43, 631-641.

(11) Zhao, W.; Brook, M. A.; Li, Y. ChemBioChem 2008, 9, 2363-2371.

(12) Bialopiotrowicz, T.; Janczuk, B. J. Surfactants and Deterg. 2001, 4, 287-292.

(13) Julian, E.; Cama, M.; Martinez, P.; Luquin, M. J. Immunol. Methods 2001, 251, 21-30.

(14) Sentandreu, M. n.; Aubry, L.; ToldrÃ $i$, F.; Ouali, A. Eur. Food Res. Technol. 2007, 224, 623628.

(15) Gudipati, C. S.; Finlay, J. A.; Callow, J. A.; Callow, M. E.; Wooley, K. L. Langmuir 2005, 21, 3044-3053.

(16) Sharma, S.; Johnson, R. W.; Desai, T. A. Biosens. Bioelectron. 2004, 20, 227-239.

(17) Karakoti, A. S.; Das, S.; Thevuthasan, S.; Seal, S. Angew. Chem. Int. Ed. 2011, 50, 1980-1994.

(18) Azegami, S.; Tsuboi, A.; Izumi, T.; Hirata, M.; Dubin, P. L.; Wang, B.; Kokufuta, E. Langmuir 1999, 15, 940-947. 
(19) Yoshimoto, K.; Nishio, M.; Sugasawa, H.; Nagasaki, Y. J. Am. Chem. Soc. 2010, 132, 79827989.

(20) Nagasaki, Y.; Kobayashi, H.; Katsuyama, Y.; Jomura, T.; Sakura, T. J. Colloid Interf. Sci. 2007, $309,524-530$.

(21) Lakshmipriya, T.; Fujimaki, M.; Gopinath, S. C. B.; Awazu, K.; Horiguchi, Y.; Nagasaki, Y. Analyst 2013, 138, 2863-2870.

(22) Otsuka, H.; Nagasaki, Y.; Kataoka, K. Biomacromolecules 2000, 1, 39-48.

(23) Dalsin, J. L.; Lin, L.; Tosatti, S.; Voros, J.; Textor, M.; Messersmith, P. B. Langmuir 2004, 21, 640-646.

(24) Kamimura, M.; Miyamoto, D.; Saito, Y.; Soga, K.; Nagasaki, Y. Langmuir 2008, 24, 88648870.

(25) Zhang, X.; Huang, P.-J. J.; Servos, M. R.; Liu, J. Langmuir 2012, 28, 14330-14337.

(26) Miller-Jaster, K.; Petrie Aronin, C.; Guilford, W. Cell. Mol. Bioeng. 2012, 5, 44-51.

(27) Zhang, X.; Servos, M. R.; Liu, J. J. Am. Chem. Soc. 2012, 134, 9910-9913.

(28) Lang, N. J.; Liu, B.; Zhang, X.; Liu, J. Langmuir 2013.

(29) Shin, J.; Zhang, X.; Liu, J. J. Phys. Chem. B 2012, 116, 13396-13402.

(30) Miyoshi, D.; Sugimoto, N. Biochimie 2008, 90, 1040-1051.

(31) Miyoshi, D.; Matsumura, S.; Nakano, S.-i.; Sugimoto, N. J. Am. Chem. Soc. 2003, 126, 165-169.

(32) Zaki, A.; Dave, N.; Liu, J. J. Am. Chem. Soc. 2012, 134, 35-38.

(33) Poirel, L.; Naas, T.; Nicolas, D.; Collet, L.; Bellais, S.; Cavallo, J. D.; Nordmann, P. Antimicrob. Agents Ch. 2000, 44, 891-897.

(34) Dave, N.; Liu, J. ACS Nano 2011, 5, 1304-1312.

(35) Ip, A. C. F.; Liu, B.; Huang, P.-J. J.; Liu, J. Small 2013, 9, 1030-1035.

(36) Nazarenko, I.; Pires, R.; Lowe, B.; Obaidy, M.; Rashtchian, A. Nucleic Acids Res. 2002, 30, 2089-2195. 
(37) Knowles, D. B.; LaCroix, A. S.; Deines, N. F.; Shkel, I.; Record, M. T. Proc. Natl. Acad. Sci. U.S.A. 2011, 108, 12699-12704.

(38) Viswanatha, T.; Marrone, L.; Goodfellow, V.; Dmitrienko, G. I. Methods Mol. Med. 2008, 142, 239-60.

(39) Kuga, S. J. Chromatogr. A 1981, 206, 449-461. 